\title{
Absorbed doses in salivary and thyroid glands from panoramic radiography and cone beam computed tomography
}

\author{
Katia Regina Heiden ${ }^{*}$, Anna Silvia Penteado Setti da Rocha ${ }^{2}$, Danielle Filipov ${ }^{2}$, \\ Cristina Berrocal Salazar ${ }^{3}$, Ângela Fernandes ${ }^{3}$, Fernando Henrique Westphalen ${ }^{3}$, \\ João Antonio Palma Setti ${ }^{1}$
}

${ }^{1}$ Graduate Program in Biomedical Engineering, Federal University of Technology of Paraná, Curitiba, PR, Brazil.

${ }^{2}$ Physics Department, Federal University of Technology of Paraná, Curitiba, PR, Brazil.

${ }^{3}$ Stomatology Department, Federal University of Paraná, Curitiba, PR, Brazil.

\begin{abstract}
Introduction: Panoramic radiography and cone beam computed tomography (CBCT) are very important in the diagnosis of oral diseases, however patients are exposed to the risk of ionizing radiation. This paper describes our study aimed at comparing absorbed doses in the salivary glands and thyroid due to panoramic radiography and $\mathrm{CBCT}$ and estimating radiation induced cancer risk associated with those methods. Methods: Absorbed doses of two CBCT equipment (i-CAT ${ }^{\circledR}$ Next Generation and SCANORA ${ }^{\circledR}$ 3D) and a digital panoramic device (ORTHOPANTOMOGRAPH ${ }^{\circledR}$ OP200D) were measured using thermoluminescent dosimeters loaded in an anthropomorphic phantom on sublingual, submandibular, parotid and thyroid glands. Results: Absorbed doses in the $\mathrm{i}-\mathrm{CAT}^{\circledR}$ device ranged between $0.02(+/-0.01)$ and $2.23 \mathrm{mGy}(+/-0.03)$, in the SCANORA ${ }^{\mathrm{TM}}$ device ranged from $0.01(+/-0.01)$ to $2.96 \mathrm{mGy}(+/-0.29)$ and in the ORTHOPANTOMOGRAPH ${ }^{\circledR}$ OP200D ranged between $0.04 \mathrm{mGy}$ and $0.78 \mathrm{mGy}$. The radiation induced cancer risk was highlighted in the salivary glands, which received higher doses. The protocols that offer the highest risk of cancer are the high resolution protocols of CBCT equipment. Conclusion: $\mathrm{CBCT}$ exposes patients to higher levels of radiation than panoramic radiography, so the risks and benefits of each method should be considered. The doses in CBCT were dependent on equipment and exposure parameters, therefore adequate selection minimizes the radiation dose.
\end{abstract}

Keywords Cone beam computed tomography, Panoramic radiograph, Radiation dose, Thermoluminescent dosimetry.

\section{Introduction}

In order to optimize diagnosis and treatments, new imaging technologies and methods have been adopted in many health related areas. This is the case of cone-beam computed tomography (CBCT) exams, which has gained increased popularity due to its wide range of applicability, reduced cost (when compared with the conventional CT) and 3D image quality, placing it on the edge of complementary imaging exams in dentistry. It's benefits have been widely reported, however CBCT scans also

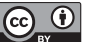

This is an Open Access article distributed under the terms of the Creative Commons Attribution License, which permits unrestricted use, distribution, and reproduction in any medium, provided the original work is properly cited.

How to cite this article: Heiden KR, Rocha ASPS, Filipov D, Salazar CB, Fernandes A, Westphalen FH, Setti JAP. Absorbed doses in salivary and thyroid glands from panoramic radiography and cone beam computed tomography. Res Biomed Eng. 2018; 34(1):31-36. DOI: $10.1590 / 2446-4740.03717$

*Corresponding author: Graduate Program in Biomedical Engineering, Federal University of Technology of Paraná, Av. Sete de Setembro, 3165, Rebouças, CEP 80230-901, Curitiba, PR, Brazil. E-mail: katiah@alunos.utfpr.edu.br

Received: 07 July 2017 / Accepted: 23 January 2018 expose the patient to biologic risks of ionizing radiation (Akyalcin et al., 2013; Li, 2013; Suomalainen et al., 2015).

Several studies demonstrate CBCT's higher radiation dose when comparing to intra-oral or extra-oral conventional methods of x-ray (Akyalcin et al., 2013; Ludlow and Ivanovic, 2008). Grünheid et al. (2012) for example, performed a effective dose comparison between different protocols of the CBCT i-CAT ${ }^{\circledR}$ Next Generation (Imaging Sciences International, Hatfield, $\mathrm{Pa}$ ) and panoramic radiographs performed on an OP100 (Instrumentarium Dental, Finland) they found effective doses of 69.2 to $134.2 \mu \mathrm{Sv}$ in CBCT, corresponding 3.22 to 6.24 times higher compared to the effective dose found on the panoramic radiographs. In the study of Sezgin et al. (2012) effective doses ranged from 75 to $118 \mu \mathrm{Sv}$ in CBCT and in panoramic radiography the effective dose was $11 \mu \mathrm{Sv}$. Li (2013) found effective dose for panoramic radiographs is about $22 \mu \mathrm{Sv}$ and for CBCT examination the effective dose is between 61 and $134 \mu \mathrm{Sv}$. In the study by Al-Okshi et al. (2013) effective doses ranged from 10 to $129 \mu \mathrm{Sv}$ in CBCT and from 8 to $14 \mu \mathrm{Sv}$ in panoramic radiography, nevertheless all are considered low doses compared 
to all natural environmental radiation received for life (Grünheid et al., 2012).

Although radiation doses from panoramic radiographs and CBCT scans are usually low, they expose radiosensitive organs of the head and neck region to the effects of ionizing radiation. The main exposed radiosensitive organs are the salivary and thyroid glands. Since in dentistry is used a lead apron, several of that radiation is avoided, although studies demonstrate that when one thyroid collar was used in CBCT the effective dose to the thyroid gland and esophagus were reduced (Li, 2013), however others radiosensitive tissues as salivary glands received direct doses (Loubele et al., 2009).

In order to show evidence on the differences of each equipment, and protocol, only absorbed doses were calculated. However, the effective dose is the most suitable dose index to assess the patient radiation risk from a radiation-protection perspective. Such index is used to infer the equivalent whole-body dose that results in a stochastic effect, which equivalent to stochastic effect from the actual absorbed dose to those tissues irradiated in a non-uniform way (Ludlow and Ivanovic, 2008). In this sense, this study aimed at comparing the absorbed doses from panoramic radiography and $\mathrm{CBCT}$ in the salivary glands and thyroid and estimating the radiation induced cancer risk associated with those methods.

\section{Methods}

Thermoluminescent dosimeters (TLDs) were placed in an anthropomorphic phantom in regions corresponding to the salivary and thyroid glands and exposed, to evaluate the dose of a digital panoramic radiography device and two $\mathrm{CBCT}$ in these organs.

\section{Phantom}

A male anthropomorphic phantom "The Alderson Radiation Therapy (ART)" (Radiology Support Devices Long Beach, CA, USA) was used for all dose measurements. It consists in a head and neck phantom divided in 9 slices of $2.5 \mathrm{~cm}$ thick (Figure 1a). On which each slice had small holes with soft-tissue removable plugs for dosimeter placement (Figure 1b). Anthropomorphic characteristic refers to the soft-tissues density simulation to match the attenuation and radiographic properties of bone, soft-tissues and airways of the human head. This allows a reliable dose measurement in any ionizing radiation exam.

\section{Dosimeters}

A total of 16 lithium fluoride dosimeters ( $\mathrm{LiF}: \mathrm{Mg}, \mathrm{Ti})$, measuring $3.2 \mathrm{~mm} \times 3.2 \mathrm{~mm} \times 0.9 \mathrm{~mm}$, manufactured by RadPRO International GmbH (Wermelskirchen, Germany), were used. The TLDs were calibrated using the same equipment once the procedure was performed. Therefore, the X-ray beam quality was equivalent to that of the beam used in the procedure.

The dosimeters were encapsulated in pairs in numerically identified plastic envelopes, made of the same intraoral film package used in dental radiology, and distributed in the phantom according to Table 1 . Each phantom placement hole chosen contained two TLDs in order to maximize reliability.

For each slice, placement of the TLDs was carefully considered with input from a dental radiologist to ensure that there was an even spread over the different radiosensitive organs. The anatomic distribution was based on the fraction irradiated organ during a panoramic radiograph and a CBCT scan, on which we decided to

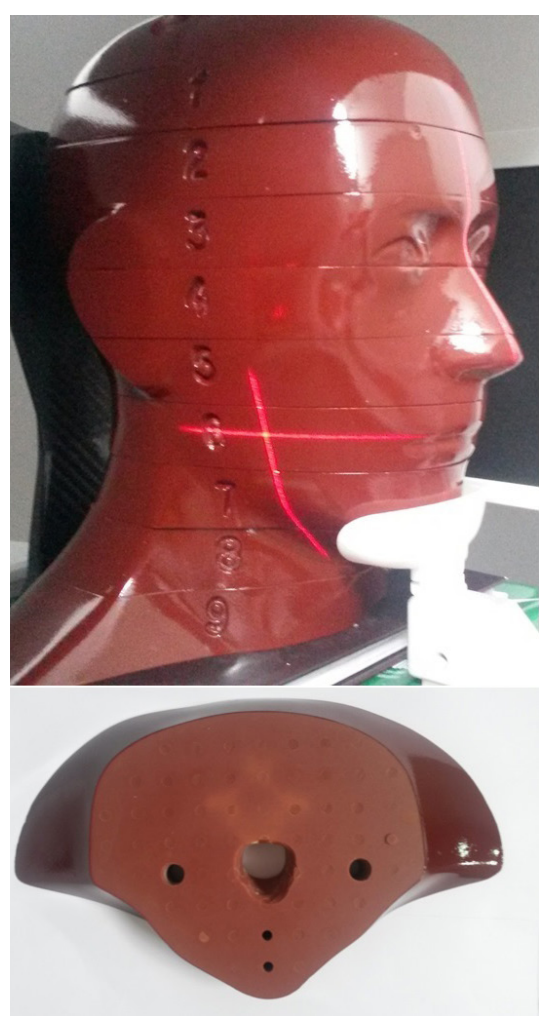

Figure 1. The Alderson Radiation Therapy phantom (ART): (a) head and neck phantom and (b) 9th slice showing the TLDs holder holes.

Table 1. TLDs localization in the phantom.

\begin{tabular}{ccc}
\hline Organ & Phantom level & TLD ID \\
\hline Thyroid surface & 9 & 1 \\
Thyroid gland & 9 & 2 \\
Sublingual gland & 7 & 3 \\
Left Submandibular gland & 7 & 4 \\
Right Submandibular gland & 7 & 5 \\
Left Parotid gland & 5 & 6 \\
Right Parotid gland & 5 & 7
\end{tabular}


choose those that were 100\% irradiated (Ludlow and Ivanovic, 2008) and those that received the highest effective doses in previous studies (Loubele et al., 2009). Following the statement of reflect critical organs known to be sensitive to radiation (Ludlow and Ivanovic, 2008; Schilling and Geibel, 2013).

Since TLDs are sensible to any source of background radiation (BG) while being transported, or in the ionizing equipment room, this radiation was also measured in order to discount it from de absorb dose in each TLD placed in the phantom.

A RA04 TLD Reader, also from RadPro, was used for the reading procedures.

\section{Exposure parameters and protocols}

The two CBCT devices used were the i-CAT ${ }^{\circledR} \mathrm{Next}$ Generation (Imaging Science International, Hatfield, Pa) and the SCANORA ${ }^{\text {TM }}$ 3D (Soredex, Tuusula, Finland) and for the panoramic device the Orthopantomograph OP200D (Instrumentarium Dental, Tuusula, Finland) was used. The phantom was placed under each device specifications, with the median sagittal plane perpendicular to the ground and the occlusal plane parallel to the scan rotation plane, as show in Figure 2.

To verify if each region of interest was in the field of view (FOV), one shoot was carried on. During scanning,

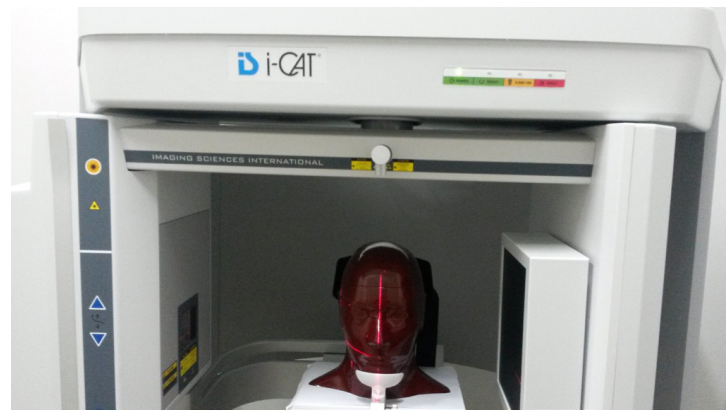

Figure 2. Phantom positioned on the i-CAT ${ }^{\circledast}$ Next Generation. the phantom was oriented with the occlusal plane parallel to the scan rotation plane to ensure the reproducibility of the phantom position and to minimize phantom shift or rotation (Pauwels et al., 2012).

In order to maintain its reproducibility the exposure parameters were divided in protocols (Table 2) according to the FOV, voxel size and exposure time, on which each protocol well-matched with the dentomaxillofacial applications of CBCT and panoramic radiograph. Therefore we divided in large FOVs, that permit simultaneous imaging of the complete base of the skull as well as maxillofacial anatomy extending from the frontal process to the base of the chin, that are used for orthodontic diagnosis and smaller FOVs, that are used in endodontics or implantology, for example.

\section{Measurements}

Doses were measured in the thyroid and salivary glands. To calculate the absorbed dose (D) in these organs, it was made an average from each pair of irradiated TLDs. From this value, it was subtracted the mean value from the BG. Then, it was divided by the number of scans. The radiation exposure doses of the TLDs are too small to be measured with reliability; therefore ten scans for each protocol were used to enlarge the dose substantially above the background dose values.

To calculate the equivalent dose $\left(\mathrm{H}_{\mathrm{T}}\right)$ in microsieverts $(\mu \mathrm{Sv})$ the Equation 1 was used:

$\mathrm{H}_{\mathrm{T}}=\mathrm{D}_{\mathrm{T}} \times \mathrm{W}_{\mathrm{R}}$

where $\mathrm{D}_{\mathrm{T}}$ is the average absorb dose for each particular tissue and $\mathrm{W}_{\mathrm{R}}$ is the radiation weighting factor, for the particular type and energy of radiation involved, which in the case of X-radiation is 1 (Loubele et al., 2009).

All collected data and the calculated absorb doses was tabulated and organized statistically using the SPSS ${ }^{\circledR}$ program. Each paired comparison was made using the one factor ANOVA.

Table 2. Exposure parameters of the CBCT and conventional X-ray imaging devices used

\begin{tabular}{|c|c|c|c|c|c|c|}
\hline Equipment & $\begin{array}{c}\text { Tube } \\
\text { voltage } \\
(\mathbf{k V})\end{array}$ & FOV (cm) & $\begin{array}{c}\text { Voxel size } \\
(\mathrm{mm})\end{array}$ & $\begin{array}{l}\text { Time of } \\
\text { scan (s) }\end{array}$ & mAs & Categorization \\
\hline i-CAT ${ }^{\circledR}$ Next Generation & 120 & $8 \times 8$ & 0.125 & 26.9 & 37.07 & $\mathrm{HR}^{*}$ \\
\hline i-CAT ${ }^{\circledR}$ Next Generation & 120 & $8 \times 8$ & 0.3 & 8.9 & 18.54 & Standard small \\
\hline i-CAT ${ }^{\circledR}$ Next Generation & 120 & $23 \times 17$ & 0.3 & 17.8 & 37.1 & Standard large \\
\hline i-CAT ${ }^{\circledR}$ Next Generation & 120 & $23 \times 17$ & 0.3 & 8.9 & 18.54 & Fast large \\
\hline SCANORA ${ }^{\mathrm{TM}} 3 \mathrm{D}$ & 90 & $6 \times 6$ & 0.133 & 20 & 56.25 & $\mathrm{HR}^{*}$ \\
\hline SCANORA $^{\mathrm{TM}} 3 \mathrm{D}$ & 90 & $6 \times 6$ & 0.2 & 13 & 37.5 & Standard small \\
\hline SCANORA ${ }^{\mathrm{TM}} 3 \mathrm{D}$ & 90 & $13 \times 14.5$ & 0.35 & 20 & 56.25 & Standard large \\
\hline ORTHOPANTOMOGRAPH OP200 D & 66 & 14.7 & & 14.1 & & \\
\hline
\end{tabular}




\section{Risk of cancer}

The estimation of radio-induced risk of cancer in the organs of interest followed the reports of the Biological Effects of Ionizing Radiation - BEIR VII (National..., 2006) that considers age, sex and organ as measurement parameters. BEIR VII was calculated according to Equation 2.

$\mathrm{R}=\mathrm{r}_{\mathrm{T}} \cdot \mathrm{H}_{\mathrm{T}}$

where $\mathrm{R}$ is the effective risk of cancer incidence, $\mathrm{r}_{\mathrm{T}}$ is the cancer risk specific to the tissue or organ and $\mathrm{H}_{\mathrm{T}}$ is the equivalent dose in tissue.

\section{Results}

The mean absorbed doses varied according to the equipment and protocol used, as Table 3 provides. Absorbed doses for the $\mathrm{i}-\mathrm{CAT}^{\circledR}$ device ranged between $0.02(+/-0.01)$ and $2.23 \mathrm{mGy}(+/-0.03)$, in the SCANORA ${ }^{\mathrm{TM}}$ device ranged between $0.01(+/-0.01)$ and $2.96 \mathrm{mGy}(+/-0.29)$ and between $0.04(+/-0.02)$ and $0.78 \mathrm{mGy}(+/-0.07)$ when the adult protocol for panoramic radiograph was applied.
The results demonstrate that the thyroid gland was the organ that received the lowest doses. The highest dose found on the thyroid gland was $0.22 \mathrm{mGy}$, while the lowest dose found on the salivary glands in general was of $0.26 \mathrm{mGy}$.

In a general point of view, the larger doses were found in the i-CAT ${ }^{\circledast}$ device, when the protocol of the smallest FOV was used in high-resolution modality, followed by the SCANORA ${ }^{\mathrm{TM}}$ HR protocol.

When the ANOVA test was applied, a statistically significant difference was found between the HR i-CAT ${ }^{\circledR}$ protocol and the panoramic radiographic equipment.

The estimated risk of radio-induced cancer is shown in Table 4. The risk was calculated based on a 20 -year-old adult, the age with the highest probability of developing cancer, according to the BEIR VII. The values refer to the number of cases per 100.00 people exposed to a single dose of $0.1 \mathrm{~Gy}$.

Radiation induced cancer risk was highlighted in the salivary glands. The protocols that offer the highest risk of cancer were the high resolution protocols of the CBCT equipment.

Table 3. Mean absorbed doses (mGy) in assessed head and neck organs.

\begin{tabular}{|c|c|c|c|c|c|c|c|c|}
\hline & \multicolumn{7}{|c|}{ Cone beam } & \multirow{3}{*}{$\begin{array}{c}\text { Panoramic } \\
\text { x-ray }\end{array}$} \\
\hline & \multicolumn{4}{|c|}{ i-CAT ${ }^{\circledR}$ Next Generation } & \multicolumn{3}{|c|}{ Scanora $^{\text {TM }}$ 3D } & \\
\hline & $\begin{array}{l}\text { HR* }^{*} \\
\text { small }\end{array}$ & $\begin{array}{c}\text { Standard } \\
\text { small }\end{array}$ & $\begin{array}{c}\text { Standard } \\
\text { large }\end{array}$ & Fast larg & $\begin{array}{l}\text { HR* }^{*} \\
\text { small }\end{array}$ & $\begin{array}{c}\text { Standard } \\
\text { small }\end{array}$ & $\begin{array}{c}\text { Standard } \\
\text { large }\end{array}$ & \\
\hline Thyroid surface & $0.13 \pm 0.02$ & $0.04 \pm 0.02$ & $0.18 \pm 0.02$ & $0.07 \pm 0.01$ & $0.12 \pm 0.01$ & $0.01 \pm 0.01$ & $0.02 \pm 0.01$ & $0.04 \pm 0.02$ \\
\hline Thyroid gland & $0.16 \pm 0.02$ & $0.02 \pm 0.04$ & $0.22 \pm 0.005$ & $0.07 \pm 0.01$ & $0.12 \pm 0.01$ & $0.01 \pm 0.01$ & $0.01 \pm 0.01$ & $0.23 \pm 0.02$ \\
\hline Sublingual gland & $2.23 \pm 0.03$ & $1.16 \pm 0.03$ & $0.78 \pm 0.02$ & $0.54 \pm 0.03$ & $0.93 \pm 0.06$ & $1.08 \pm 0.03$ & $0.77 \pm 0.02$ & $0.26 \pm 0.02$ \\
\hline $\begin{array}{l}\text { Left submandibular } \\
\text { gland }\end{array}$ & $1.51 \pm 0.01$ & $0.84 \pm 0.04$ & $0.89 \pm 0.06$ & $0.61 \pm 0.05$ & $0.57 \pm 0.01$ & $0.50 \pm 0.03$ & $0.59 \pm 0.02$ & $0.78 \pm 0.07$ \\
\hline $\begin{array}{l}\text { Right submandibular } \\
\text { gland }\end{array}$ & $1.82 \pm 0.04$ & $0.94 \pm 0.05$ & $1.11 \pm 0.03$ & $0.71 \pm 0.02$ & $0.51 \pm 0.01$ & $0.27 \pm 0.01$ & $0.34 \pm 0.005$ & $0.31 \pm 0.03$ \\
\hline Left parotid gland & $1.88 \pm 0.03$ & $1.11 \pm 0.01$ & $1.02 \pm 0.01$ & $0.80 \pm 0.05$ & $2.96 \pm 0.29$ & $1.13 \pm 0.02$ & $1.43 \pm 0.07$ & $0.33 \pm 0.02$ \\
\hline Right parotid gland & $1.50 \pm 0.06$ & $0.82 \pm 0.04$ & $1.12 \pm 0.03$ & $0.78 \pm 0.05$ & $1.27 \pm 0.02$ & $0.52 \pm 0.04$ & $0.53 \pm 0.08$ & $0.29 \pm 0.03$ \\
\hline
\end{tabular}

HR* High resolution.

Table 4. Radiation induced cancer risk on a 20-year-old adult.

\begin{tabular}{|c|c|c|c|c|c|c|c|c|}
\hline & \multicolumn{7}{|c|}{ Cone Beam } & \multirow{3}{*}{$\begin{array}{c}\begin{array}{c}\text { Panoramic } \\
\text { x-ray }\end{array} \\
\text { OP 200D } \\
\text { Adult } \\
\text { protocol }\end{array}$} \\
\hline & \multicolumn{4}{|c|}{ i-CAT ${ }^{\circledR}$ Next Generation } & \multicolumn{3}{|c|}{ ScanoraTM 3D $^{T M}$} & \\
\hline & $\begin{array}{l}\text { HR* } \\
\text { small }\end{array}$ & $\begin{array}{c}\text { Fast } \\
\text { small } \\
\end{array}$ & $\begin{array}{c}\text { Standard } \\
\text { large }\end{array}$ & Fast larg & $\begin{array}{l}\text { HR* }^{*} \\
\text { small }\end{array}$ & $\begin{array}{c}\text { Standard } \\
\text { small }\end{array}$ & $\begin{array}{c}\text { Standard } \\
\text { large }\end{array}$ & \\
\hline Thyroid surface & 0.147 & 0.045 & 0.203 & 0.079 & 0.136 & 0.011 & 0.023 & 0.045 \\
\hline Thyroid & 0.181 & 0.023 & 0.023 & 0.079 & 0.136 & 0.011 & 0.011 & 0.260 \\
\hline Sublingual gland & 7.202 & 3.747 & 2.519 & 1.744 & 3.003 & 3.488 & 2.487 & 0.8400 \\
\hline Left submandibular gland & 4.877 & 2.713 & 2.874 & 1.970 & 1.841 & 1.615 & 1.905 & 2.519 \\
\hline Right submandibular gland & 5.879 & 3.036 & 3.585 & 2.293 & 1.647 & 0.872 & 1.098 & 1.001 \\
\hline Left parotid gland & 6.072 & 3.585 & 3.294 & 2.584 & 9.560 & 3.650 & 4.619 & 1.065 \\
\hline Right parotid gland & 4.845 & 2.649 & 3.618 & 2.519 & 41.021 & 1.680 & 1.712 & 0.937 \\
\hline
\end{tabular}

$\mathrm{HR}^{*}=$ High resolution 


\section{Discussion}

Our experimental research was designed to calculate the doses that the most sensible head and neck organs can absorb in the most frequent exam protocols and setting parameters of CBCT. Also, we intended to compare the absorbed doses between each device, based on values assessed for an adult protocol on panoramic exams. As such, we were in search of parameters to decide whether to use conventional X-ray images or CBCT scans for any particular case, knowing the correct absorbed doses associated with each protocol. To our knowledge this is the first study using the OP 200D equipment, and comparing its absorb doses to other CBCT devices.

As we were looking for evidences of differences among the equipment and protocols, only the absorbed doses were calculated. We believe that the effective dose should be used as the dose index to assess the patient radiation risk from a radiation-protection perspective (Pauwels et al., 2012).

Table 3 shows that the highest doses were found in the salivary glands, which is in line with current literature (Gijbels et al., 2005; Lecomber et al., 2000; 2001). As seen in Table 4, the probability of cancer is higher for the salivary glands. Thus the exposures should be optimized in order to reduce the deleterious effects of radiation in these organs.

In 2012, the European Commission published the Radiation protection No 172, which is an evidence-based guide for the safe use of CBCT in dental radiology (European..., 2012). This guide is part of the SEDENTEXCT project, which aims to acquire the main scientific information on the clinical use of CBCT, in addition to presenting the basic principles of radiological protection, such as justification, optimization of exposures, user training and quality assurance in $\mathrm{CBCT}$.

The use of CBCT in dentistry should only be justified if it provides a new information that cannot be obtained by panoramic radiography or another technique with a lower dose of radiation (Jaju and Jaju, 2015; Pauwels, 2015).

If the examination is justified, it should be optimized in order to offer the lowest radiation dose. An important optimization principle in dental CBCT relates to the choice of the appropriate volume size and the choice between high and low-dose for each examination. In this study, doses obtained using the small FOV at high resolution were $46 \%$ higher in the i-CAT ${ }^{\circledast}$ equipment and $45 \%$ higher in the SCANORA ${ }^{\mathrm{TM}}$ equipment, when compared to the doses obtained using the standard resolution.

Protocols should be based on the purpose of the examination. Complex endodontic cases may require small FOVs and high dose protocols, which achieve better image quality due to their high resolution, while in planning of implants, low dose protocols are sufficient for evaluation of bone quality, limiting the FOV to the area of interest (Pauwels, 2015).

When comparing the doses obtained in the different CBCT protocols at the doses obtained in panoramic radiography, we conclude that a $\mathrm{CBCT}$ examination can be equivalent to 4.5 panoramic radiographs, considered few compared to what is gain on the diagnosis.

It's important to recall the responsibility that the professional has on the moment of asking for an image exam, an important reflection must to be done, on which the analysis of the technique has to be based on the need of diagnostic information. Depending of the case, if lots of radiographies have to be taken, the absorbed radiation dose will approximate to that of CBCT values, resulting in less information.

Despite providing significant improvement in the diagnosis outcomes and treatment plans of dental and maxillofacial disorders, CBCT scans expose patients to higher levels of radiation when compared to the panoramic x-ray equipment. These exposures can be minimized depending on the chosen protocol. Protocols that utilize small FOV, with a voxel size of greater and lesser time are preferable to reduce radiation doses.

\section{References}

Akyalcin S, English JD, Abramovitch KM, Rong XJ. Measurement of skin dose from cone-beam computed tomography imaging. Head Face Med. 2013; 9(28):28. PMid:24192155.

Al-Okshi AM, Nilsson M, Petersson A, Wiese M, Lindh C. Using GafChromic film to estimate the effective dose from dental cone beam CT and panoramic radiography. Dentomaxillofac Radiol. 2013; 42(7):1-8. PMid:23610090. http://dx.doi. org/10.1259/dmfr.20120343.

European Commission. Radiation protection $n^{\circ} 172$ : cone beam $\mathrm{CT}$ for dental and maxillofacial radiology: evidence based guidelines [internet] Brussels; 2012 [cited 2018 Jan 1]. Available from: http://ec.europa.eu/energy/nuclear/radiation_protection/ doc/publication/172.pdf

Gijbels F, Jacobs R, Bogaerts R, Debaveye D, Verlinden S, Sanderink G. Dosimetry of digital panoramic imaging. Part I: patient exposure. Dentomaxillofac Radiol. 2005; 34(3):145-9. PMid:15897284. http://dx.doi.org/10.1259/dmfr/28107460.

Grünheid T, Kolbeck Schieck JR, Pliska BT, Ahmad M, Larson BE. Dosimetry of a cone-beam computed tomography machine compared with a digital x-ray machine in orthodontic imaging. Am J Orthod Dentofacial Orthop. 2012; 141(4):436-43. PMid:22464525. http://dx.doi.org/10.1016/j.ajodo.2011.10.024.

Jaju PP, Jaju SP. Cone-beam computed tomography: time to move from ALARA to ALADA. Imaging Sci Dent. 2015; 45(4):263-5. PMid:26730375. http://dx.doi.org/10.5624/ isd.2015.45.4.263. 
Lecomber AR, Downes SL, Mokhtari M, Faulkner K. Optimisation of patient doses in programmable dental panoramic radiography. Dentomaxillofac Radiol. 2000; 29(2):107-12. PMid:10808225. http://dx.doi.org/10.1038/sj.dmfr.4600513.

Lecomber AR, Yoneyama Y, Lovelock DJ, Hosoi T, Adams AM. Comparison of patient dose from imaging protocols for dental implant planning using conventional radiography and computed tomography. Dentomaxillofac Radiol. 2001; 30(5):255-9. PMid:11571544. http://dx.doi.org/10.1038/ sj.dmfr.4600627.

Li G. Patient radiation dose and protection from cone-beam computed tomography. Imaging Sci Dent. 2013; 43(2):63-9. PMid:23807928. http://dx.doi.org/10.5624/isd.2013.43.2.63.

Loubele M, Bogaerts R, Van Dijck E, Pauwels R, Vanheusden S, Suetens P, Marchal G, Sanderink G, Jacobs R. Comparison between effective radiation dose of CBCT and MSCT scanners for dentomaxillofacial applications. Eur J Radiol. 2009; 71(3):461-8. PMid:18639404. http://dx.doi.org/10.1016/j. ejrad.2008.06.002.

Ludlow JB, Ivanovic M. Comparative dosimetry of dental CBCT devices and 64- slice CT for oral and maxillofacial radiology. Oral Surg Oral Med Oral Pathol Oral Radiol Endod. 2008; 106(1):106-14. PMid:18504152. http://dx.doi.org/10.1016/j. tripleo.2008.03.018.
National Research Council - NRC. Health risks from exposure to low levels of ionizing radiation: BEIR VII. Washington: The National Academies Press; 2006.

Pauwels R, Beinsberger J, Collaert B, Theodorakou C, Rogers J, Walker A, Cockmartin L, Bosmans H, Jacobs R, Bogaerts R, Horner K. Effective dose range for dental cone beam computed tomography scanners. Eur J Radiol. 2012; 81(2):267-71. PMid:21196094. http://dx.doi.org/10.1016/j.ejrad.2010.11.028.

Pauwels R. Cone beam CT for dental and maxillofacial imaging: dose matters. Radiat Prot Dosimetry. 2015; 165(1-4):156-61. PMid:25805884. http://dx.doi.org/10.1093/rpd/ncv057.

Schilling R, Geibel MA. Assessment of the effective doses from two dental cone beam CT devices. Dentomaxillofac Radiol. 2013; 42(5):42. PMid:23420855. http://dx.doi.org/10.1259/ dmfr.20120273.

Sezgin OS, Kayipmaz S, Yasar D, Yilmaz AB, Ozturk MH. Comparative dosimetry of dental cone beam computed tomography, panoramic radiography, and multislice computed tomography. Oral Radiol. 2012; 28(1):32-7. http://dx.doi. org/10.1007/s11282-011-0078-5.

Suomalainen A, Pakbaznejad Esmaeili E, Robinson S. Dentomaxillofacial imaging with panoramic views and cone beam CT. Insights Imaging. 2015; 6(1):1-16. PMid:25575868. http://dx.doi.org/10.1007/s13244-014-0379-4. 